Revista Iberoamericana, Vol. LXXIV, Núm. 225, Octubre-Diciembre 2008, 1131-1148

\title{
POÉTICAS DE GÉNERO EN LA NOVELA LATINOAMERICANA; DOS CASOS: JOSÉ LEZAMA LIMA Y JUAN CARLOS ONETTI
}

POR

Roberto ECHAVARREN

En 1895, el año del proceso y la condena a OscarWilde, sepublicó, aparentemente sin problemas con la censura, la primer novela homoerótica del Brasil: Bom Crioulo. El autor, Adolfo Caminha, había servido en la Marina, y la historia que cuenta probablemente se basa en algún hecho que le tocó de cerca o que conoció "desde adentro" en sus días de servicio.

Un crimen de pasión: un gigantesco musculoso marino negro, a quien todos temen cuando borracho, se hace amigo de un rubio portugués del estado sureño de Santa Catarina, un grumete de quince años. Poco antes Jules Verne había escrito Un capitán de quince años, que contenía episodios crueles pero aptos para niños.

El negro conocido con el apodo de "Bom Crioulo" se enamora de Alexis, el grumete claro adolescente. El barco donde trabajan fondea en el puerto de Rio de Janeiro y ellos se trasladan a una pensión donde conviven en connubio durante un año.

Aprecio ese naturalismo brasilero más que a Emilio Zola. Descripciones atrevidas, atención al detalle y a la figura justa, un espíritu de investigación, y el impulso de examinar cuestiones que no habían sido tratadas antes por parte de un escritor letrado, frecuentador de la poesía parnasiana y dueño de una perspectiva docta, allegado a las ciencias sociales y a la biología.

En la novela, los dos personajes, unidos por una pasión carnal y por una amistad tierna, están vistos a la vez desde dentro y desde fuera: la voz narrativa simpatiza con sus fantasías y emociones, y a la vez diseña el territorio donde este affair es posible: Rio de Janeiro, una ciudad semitropical, asiento del gobierno, refinada, tolerante con los placeres. La pederastia allí no es una rareza, no da lugar a medidas represivas particulares.

Resulta conmovedora la integridad del amor de Bom Crioulo por su jovencito; lejos de ser presentado como vicioso o libertino, el negro descubre el amor por primera vez y se entrega de cuerpo y alma. El joven grumete, después de un tiempo, no puede corresponderle; Bom Crioulo descubre su traición y lo mata. 
Una obra tan franca acerca de este asunto resultaba impensable en la América hispana de entonces, igual que en Europa. En Rusia, sólo después de la revolución de 1905, al aflojarse la censura zarista, se publicó una novela de contenido abiertamente homoerótico: Alas, de Mijail Kuzmin. Cabe señalar que este período de tolerancia se clausuró con el golpe de Lenin en octubre de 1917.

El segundo hito brasilero es Grande Sertão: Veredas (1956) de João Guimarães Rosa. Al decir de Antonio Cándido, allí culmina el proceso personalísimo de invención de una lengua literaria, elaborada a partir de lo peculiar de una región. La novela se destaca por un conjunto de cualidades que la transforman en uno de los mayores logros de la lengua portuguesa. “Grande Sertão: Veredas es un largo monólogo de seiscientas páginas, sin divisiones, en que un viejo hacendado, antiguo bandido y jefe de cuadrilla narra su vida de caballería sertanista. El problema central es el de la opción ética, en los límites del bien y del mal, simbolizada por el pacto con el demonio. Durante todo el tiempo, la atracción equívoca por un compañero de armas [...] mantiene la oscilación moral, la ambigüedad, la relatividad de las fronteras" (99).

Después de mencionar estas obras fundadoras, quiero detenerme en el análisis de la narrativa de dos contemporáneos hispánicos de Guimarães Rosa: José Lezama Lima y Juan Carlos Onetti.

La novela de Lezama, Paradiso (1966), tuvo problemas con la censura en Cuba en el momento de su aparición, donde ya se habían instalado campos de trabajo forzado para homosexuales y otros indeseables.

DisCuSión del EROS EN PARADISO

El capítulo IX de Paradiso nos presenta al protagonista, José Cemí, en conversación con sus dos mejores amigos, Fronesis y Foción.

De pronto, a través de patios y corredores de la universidad se propaga un rumor escandaloso: dos atletas remeros, sorprendidos en pleno acto de sodomía por un testigo, han sido denunciados y expulsados de la institución.

Los sorprendidos en pleno coito son Baena Albornoz, capitán de remeros de la universidad, penetrado por uno de los miembros de su equipo, el "novato Leregas", dueño de un glande de proporciones excepcionales.

Baena Albornoz era conocido por su reciedumbre y su carácter de mataputos. Al entrar a un bar expulsaba del sitio a quienes consideraba maricones; su inspección eliminaba no sólo a aquellos visiblemente amanerados, sino también a los que "tapaban” su tendencia. Baena Albornoz corresponde a una figura célebre en la literatura a partir del personaje del Barón de Charlus, de Proust: un homosexual que profesa ser hipermasculino y enemigo de los desviados a fin de confundir cualquier rumor acerca de su persona. 
Paradiso describe el ayuntamiento con una metáfora geográfica extraída del comienzo de Viaje al centro de la tierra de Jules Verne. En una de las cavidades del volcán Sneffels Jökull, en la costa occidental de Islandia, el novelista francés, quizá bajo la impresión del extraño nombre, o de las columnas basálticas del volcán, cuyo aspecto es semejante a un inmenso pulpo, situó la entrada al centro terrestre.

Leemos en Paradiso: "Pasó al sótano", donde se ocultaban los atletas para gozar, "el recuerdo del cráter de Yoculo" (245). Enclave geográfico, zona del cuerpo coinciden en una morfología equivalente: la entrada al centro de la tierra corresponde al agujero anal. Es como si la penetración estimulara una vista "en caverna” -como si una endoscopía del intestino equivaliera a la inspección de una gruta de la masa terrestre-. Si, según Rimbaud, “yo es otro", ¿quién es este "yoculo”, este yo del culo? Jökull, je-cul en francés, conforma una criatura visionaria hecha de ojos y culo. Quizá el "animal-carbunclo": destila luz propia en noche cavernosa e ilumina su propio camino (según el ensayo de Lezama "Sierpe de Don Luis de Góngora”).

La clarividencia es siempre conflictiva para el escritor. Aquí la excitación anal es llamada "fuego del nacimiento malo" (245). Y alternativamente: el lugar donde se derrama un esperma estéril, como si el autor estuviera de acuerdo con la doctrina cristiana según la cual el sexo se justifica sólo en aras de la reproducción. A pesar de ese supuesto reparo, la experiencia del coito anal es descrita aquí con regodeo y culmina en un logrado éxtasis:

Un glande en extremo tenso apuntalaba un techo salpicado de gránulos de azufre, estrellas errantes y cometas, que al reventar en los acantilados producían una oscuridad que marchaba siempre como un nematelminto por la circulación linfática, hasta deshacerse en la espuma del éxtasis. (245)

El joven Leregas no se excita pensando en una mujer. Ésta no es su fantasía. Trozos de cuerpo lo excitan, fragmentos desprendidos de su calentura:

Glúteos separados de las prolongaciones cariciosas de las espaldas [...] Brazos sin relación con un rostro le apretaban como cordeles, cada cordel se trocaba en una viborilla lamiendo un poro. (245)

Esta presentación por segmentos crea ante todo dudas con respecto al género del objeto deseado, o poseído. "No, no es la rubia Gräuben”, se apresura a agregar Lezama. Entonces, ¿son los glúteos de quién? ¿De un hombre, de una mujer? El género se disuelve cuando una piel de goce resucita en cada uno de sus poros. Queda sólo un “canal de las entrepiernas”, donde opera la "columna fálica”, una máquina a explosión. Se trata de un eros fuera de género, una calentura impersonal, un furioso regodeo. 
Al enterarse del escándalo, Cemí y sus dos amigos no protestan contra la sanción que expulsa a los atletas, mas el incidente dispara un coloquio entre ellos acerca del homoerotismo. Cada uno, a su turno, expone su propio punto de vista. El formato dialógico de estos tres abordajes consecutivos evoca, no en su contenido, sino en su disposición, la serie de discursos acerca del eros en El Banquete de Platón.

Fronesis es el primero en tomar la palabra.

Con su curiosidad, que todo lo recorre, los niños -dice -están abiertos a las posibilidades ancestrales, que ya no pertenecen al adulto. Todo está disponible para ellos, la ontogénesis recapitula la filogénesis: "El falo se hacía árbol o en la clavícula surgía un árbol” (247). Las fantasías infantiles recapitulan la memoria evolutiva de las especies, trayectos de la vida en un plano estratificado de consistencia. Las relaciones eróticas dejan de estar sobrecodificadas por las costumbres, dejan de ser habladas por la tradición o por las normas productivas de una sociedad histórica determinada. El niño es intempestivo, cuando no intemperante. Aún no ha descartado lo que el adulto eliminó. Se abre al impersonal espectro de una "edad de oro": "El recuerdo de esas eras fabulosas se conserva en la niñez, en la inocencia de la edad de oro, cuando es casi imposible distinguir cualquier dicotomía” (247). La identidad y la contradicción son los polos de la máquina binaria. El niño ignora la máquina binaria que dicotomiza: u hombre o mujer, o igual (idéntico) u opuesto (y también enemigo). El niño prescinde de esta dicotomía adulta. Lo semejante no es ni lo idéntico ni lo contradictorio.

En ciertos casos, la apertura de la niñez escansiona una vida entera: "Es el tiempo de una transfiguración, es el momento en que se puede volver a habitar ese estado de inocencia” (248).

El niño camina

para ir descubriendo lo exterior, pero es lo exterior que forma parte del mismo paideuma, que es esa sustancia configurativa que permite al primitivo, al niño y al poeta ser siempre creadores. (248)

El paideuma (compuesto del griego, paideia, educación, y pneuma, aire) es una noción vinculada al respirar; nombra una pedagogía de la respiración y alude a un espacio interior-exterior, una órbita de lo semejante, que engloba el aire que impele y expele. Esa órbita viva, el aire que entra y sale, determina el adentro y el afuera como íntimos, un espacio y un tiempo propios, "la misma sustancia que es espacio y tiempo, pues señala la región del hechizo y el devenir dentro de sus contornos" (248).

"El niño tiene siempre tendencia a la sexualidad semejante, es decir, a situar en el sexo [...] el otro semejante a sí mismo” (248). 
De acuerdo a Fronesis, la sensibilidad del niño es homoerótica, o más bien, autoerótica. El niño asimila lo que se compone con él (lo semejante) mientras que lo que no se asimila, lo que no se compone, no existe para él. El niño es afirmativo, positivo; la negación no es.

A partir de lo semejante, el niño y el poeta tienen la "vivencia de la divinidad, pero la palabra vivencia [...] está cargada de concepto, arranca de la unidad parmenídea” (248).

La "unidad parmenídea", vivencia unitiva con el cosmos, el entramado de un solo animal respirando en la multiplicidad de sus expresiones, hálito intensivo que se basta a sí mismo, no tiene nada que ver con la mansa secuencia, el tiempo uniforme, el discurrir de un río: "no tiene nada que ver con ese camino que anda [...], el río” (248).

Lo "semejante" construye, imanta, un plano de consistencia, una membrana, lomo rugoso por una traza de pedrerías, de montañas, sobre cuyo perfil texturado el niño pasa un dedo. Pasa un dedo sobre cualquier cresta.

La vivencia de lo semejante alterna con la conciencia aterrada de ser un apéndice perecible del proceso cósmico: "basta que encendamos una cerilla y la acerquemos a nuestro rostro y la luz adelanta al rostro”, reflejado en un espejo, "la oscura reminiscencia de una gorgona degollada, para que tiemble como si fuese a naufragar" (248).

El niño es el más amenazado por la necesidad, pero a la vez la pérdida de su yo en lo impersonal-semejante lo vuelve invulnerable:

Aquel que sigue inocente toda la vida, el que más atrae la ananké, la fatalidad, es al propio tiempo el que tiene el mejor escudo para luchar contra las fuerzas destructivas de la fatalidad o de la necesidad. (248)

Podríamos decir que para Fronesis no existe ni la homosexualidad ni la heterosexualidad. La órbita de lo semejante abarca el universo entero, en derivas no identitarias. Es una experiencia previa a las dicotomías, al error de la costumbre, que clasifican lo idéntico y lo no idéntico, lo idéntico y lo contradictorio.

El segundo en intervenir es Foción. Está enamorado de su camarada Fronesis, quien lo respeta y lo quiere como un amigo, pero no le corresponde al mismo nivel. Foción se siente rechazado. Quiere forzar una unión siempre más próxima, aunque es él mismo, por paradoja, quien pone distancia entre los dos. Considera que el objeto de su deseo es inalcanzable, vive en la carencia. Rema siempre hacia él, pero nunca lo alcanza. Su vida emocional pone el acento en vicisitudes de dolorosa privación, su centro descentrado lo separa de sí. Es un sujeto dividido, amarrado al objeto de su deseo, que no puede alcanzar. No reside en lo próximo o lo propio, tal el paideuma de Fronesis, sino en lo distanciado, un amor imposible. 
Perdió el eros infantil, la conformidad de lo semejante. Experimenta la ausencia, pero, de hecho, según el hilo argumental de la novela, es él mismo quien determina abandonar La Habana y a su amigo Fronesis para ir a vivir a Nueva York. O bien huir, o bien suicidarse. Su encaprichamiento, su fracaso, marcan su vida emocional. Foción vive su tendencia erótica como una condena gratuita. Algo que llega desde un vacío, y no se justifica, pero lo desespera.

Foción se pregunta: ¿de dónde surge la tendencia erótica?

La tendencia es "un hecho que no se puede justificar, porque es más profundo que toda justificación [...] Toda siembra [...] se abre en el espacio sin respuesta, que al fin da respuesta. Pero es una respuesta que nos es desconocida, no tiene justificación, es un bostezo del vacío” (249).

De ese fondo llega cualquier cosa inesperada. El hombre, apunta Foción, tiene la capacidad de acogerla. Así sea un dragón que nos devora el seno.

"La grandeza del hombre consiste en que puede asimilar lo que le es desconocido... el tragicómico inesperado" (249).

Más que justificar el homoerotismo, Foción se pregunta si la heterosexualidad no es -al fin y al cabo- un "error de la costumbre”, un mal hábito que sería cuestionable mantener.

"El sexo parece que tomó un camino, o se mantuvo en la costumbre de un camino que por huir del espacio vacío, se apoyó en el primer punto, los sexos, que encontró en su errancia” (251).

Los sexos, o géneros, masculino y femenino-la máquina binaria, dicotómica-, fueron el "primer punto de apoyo". Por hábito, la unión heterosexual, de los divididos y contrarios, se volvió una práctica preferente, en gran medida obligatoria. Pero, considerada desde la dimensión primigenia de la vida, se anula en el andrógino previo, o la mezcla de lo masculino o femenino, o la ausencia de ambos, que precede al dualismo: "La aparición de la mujer en el séptimo día [...] revela un estado androginal previo" (251). El andrógino es previo no sólo a la diferencia de los sexos (lo que está entre las piernas) sino también, y sobre todo, a los polos que consagra la costumbre, el sistema binario de género (lo que está entre las orejas). "Todo lo que hoy nos parece desvío sexual, surge en una reminiscencia, o en algo que yo me atrevería a llamar, sin temor a ninguna pedantería, hipertelia de la inmortalidad, [...] una busca de creación [...] la creación de algo hecho por el hombre, totalmente desconocido aún por la especie. La nueva especie justificaría toda hipertelia de la inmortalidad” (251).

Foción concibe el devenir como un ir más allá de lo humano, de lo humano convencional. La grandeza de las criaturas es aceptar lo que llega de ese vacío, abrazar la tendencia y construir a partir de ella una perspectiva acerca de la evolución de lo humano y de lo inhumano. "Algo hecho por el hombre, totalmente desconocido 
aún por la especie” (251). Más allá de la especie derivan líneas de fuga: esta "hipertelia" consiste en ir más allá del telos prefijado, del fin, del programa y de la teleología. Sólo la causa eficiente (el deseo, la tendencia) lleva a la criatura más allá de sí, pero sin una finalidad predeterminada.

Se diría que la reminiscencia remite al pasado: memoria de cosas olvidadas, que recuerda una construcción anterior. Sin embargo, Foción deriva de la reminiscencia una virtud creadora, nunca congelada, una pista para recombinar y proyectar el futuro.

El poder transformador atraviesa y perfora las costumbres, los arreglos consuetudinarios, las instituciones, va más allá de las formas establecidas en un momento dado para regir la conducta erótica, la asignación de género que recibe cada cual por parte del error de la costumbre, la dicotomía prescriptiva, que determina tanto la identidad como cuál debe ser el objeto de deseo correspondiente.

La curva de vida del individuo, de la especie, es englobada en bucles temporales más amplios, por un tiempo sideral, envolvente, que invoca nuestra máxima capacidad de apertura, un más allá sin finalidad predeterminada, ante una impensable propuesta de hipervida.

Un héroe preferido de Foción es el Conde de Villamediana:

Villamediana enamorando a la esposa del rey, raptando a su sobrina, escandalizando
en las corridas de toros, jugando a lo tahúr y despilfarrando el dinero en caballos
y piedras preciosas, haciendo burlas con sus costumbres secretas y sus amigos
clandestinos, fue una energía diabólica utilizada contra la monarquía decadente.
(254-55)

Villamediana fue una "energía diabólica” porque mezclaba lo que estaba separado, destruía el orden teológico y moral, las estructuras jurídicas de parentesco y de género. El rey lo mandó matar, un sicario lo atravesó de un flechazo, "mostrando en su costado tal agujero sanguinolento de ballesta, que aún en un toro diera horror, como dijera con espanto Góngora al huir alucinado de la corte” (255).

Y Foción concluye: "Este hechizado se destruye para destruir". Para Foción, Villamediana es un Don Juan que ha escapado a los infiernos, porque, más allá de su muerte, “continúa escapándose con un cuerpo sin sexo" (255). Un cuerpo sin sexo, no marcado, ni masculino ni femenino, un cuerpo que resiste a la máquina binaria, que no se deja dicotomizar. Sin sexo, sin género, o con $n$ sexos y sin la marca del género. Un erotismo sin asignación de género. Es un rebelde desconstructor del sistema binario.

A la pregunta acerca de dónde viene el eros o la tendencia que le toca a cada uno, Foción responde: no viene de ninguna parte, viene del vacío, no hay motivo, no hay origen; las tendencias vienen de un vacío que nos obliga a aceptar eso que 
sentimos o deseamos, sin que se nos diera parte en la elección. Por lo tanto no hay nada que justificar.

Su amigo Fronesis, que lo intersecta aquí, continúa la tarea de Foción. A la pregunta: “¿qué es desvío?” “¿qué es homosexual?”, responde: imposible fijar límites y fronteras, por el modo en que se mezclan de hecho en cada uno de nosotros las incongruencias del comportamiento de género. Nadie es un "puro" hombre; en el momento menos pensado, el supuesto hombre viril, con supuesta identidad de hombre, muestra requiebros de puta o de damisela.

En consecuencia, Fronesis descubre la homosexualidad en todas partes: un carbonero recio mete el pie en el agua fría y lanza un "ay” aniñado, sin hablar de las perversiones de los llamados heterosexuales, de los modos de excitación fetichista, de hombres que distan de desempeñar ante la mujer el rol activo programado que se esperaría de ellos.

Casi todos se mecen en una hamaca, son y no son heterosexuales, "todos aquejados por un desvío, aunque no se pudiera señalar en relación con qué centro se verificaba ese desvío" (257). Resultan, en cada caso, en uno y otro detalle, que puede ser minúsculo, "tránsfugas de su costumbre vital”, de la identidad de género que les fue adjudicada.

Consideremos a Julio César-propone Fronesis-a modo de contraejemplo del traído arriba por Foción (Villamediana).

A César sólo le preocupaba su destino imperial. No le hacía mella que sus conciudadanos, en vista de sus prácticas sexuales, le adjudicaran el rol de hombre o de mujer; eso lo dejaba indiferente. Él sabía que era ambos, o ninguno, y se comportaba en cada caso como mejor le cuadraba.

Fronesis concluye:

Es tan extensa la cantidad de sensaciones que se ocultan detrás del rostro o la máscara de la palabra homosexual, que comprende desde los aquejados por un innegable desvío [...] hasta hombres [...] que se erizan y se retuercen [...] recibiendo, con el chapuzón de las aguas, la investidura de su espíritu maternal. (257)

Cada uno tiene un comportamiento que bien pudiera ser descrito en algunos aspectos o momentos como incoherente con respecto a su rol asignado. En vez de clasificar a la gente a través de una letanía de identidades forzosas, más valdría considerar cómo se despliega en concreto cada individuo, cómo se desenvuelve el dromenon, o “medida que respira”. Esa medida, su pauta, es un conjunto de prácticas, “el hecho realizado”, y para los griegos eso era teorema, una conversación desenvuelta como un baile, la carretera donde los cuerpos hermosos van impulsados por la luz. "El dromenon era el espacio [...], una medida que respiraba" (259). Cada ser da su medida en devenir libre, por sus líneas de deriva, y baila y respira, practica alegre el poder. 
Porque "en realidad el laberinto corporal es la única forma de aprehensión de ese espacio ocupado totalmente por ese neuma o hálito universal” (260).

El espíritu de un espacio errante, un viento, se trasmuta en hálito, aliento hipostasiado en el laberinto corporal que recorre y atraviesa.

Hálito innumerable, inapresable, inasible:

a) El cuerpo es la permanencia de un oleaje innumerable [...]

b) en cada hombre esa imagen repta con mutaciones casi inapresables

c) pero ese inasible tiene la medida de su sexualidad. (260)

¿Cómo apresar un eros que puede ser deleite en cada milímetro del cuerpo? ¿Cómo definirlo? Tiene una medida, un idiolecto en cada uno, una manera, un estilo, una intensidad.

El oleaje innumerable, traslúcido, de los simulacros que atraviesan el cuerpo se acumula contra un borde de mutaciones casi inapresables, pero el inasible tiene una medida: no la sexualidad consuetudinaria, el error, sino la medida cabal: una versión de estilo.

Para pensar el sexo, considera Fronesis, tenemos que tomar en cuenta antes que nada los pulmones y el intestino. Respirar y digerir. Aparentemente los órganos de la reproducción no son "primeros" para él. Les surge además otro competidor: el cráter "Yoculo" prolongado en "el orificio interior del tubo intestinal”, un "órgano de la acción”, según las leyes de Manú. En consecuencia, Fronesis declara que no se considera capacitado para hablar así nomás de sexo. Y cede el turno al tercero de los amigos, José Cemí.

Cemí aborda el eros a partir de la tradición cristiana de los padres de la Iglesia que ensalzan la castidad y procuran neutralizar el placer y por lo tanto cualquier conducta desviante de la finalidad de la reproducción, un acto neutro, apenas correcto, dentro de condiciones apropiadas, en el marco del matrimonio.

Se detiene en San Agustín y en Santo Tomás de Aquino.

Después de haber vivido una juventud pagana ardiente, apasionado de su amigo Alipio, Agustín de Hipona resuelve repudiar su vida pasada, como si fuera una etapa apenas, no la condición de su vida entera, repudia lo que amó y considera que los pecados de lujuria homoerótica son los peores.

A esta posición tajante de alguien que fue, al menos en su juventud, atormentado por eros, José Cemí contrasta el juicio que la misma infracción (el acto contra natura) merece a Santo Tomás de Aquino. A él no lo tentaba la lujuria. Un buey que piensa, pura castidad. "Le fue otorgado el don de los ángeles en el sexo, disfrutó de una regalada castidad en la gracia” (268). El deseo de Santo Tomás está investido en su vida intelectual. Él apetece conceptos y palabras, un pensamiento teológico filosófico que sin embargo -según Cemí- no pierde la conexión con los sentidos. 
El pensamiento cristiano no puede ser sino una postrimería, de modo que Tomás vuelca su gozo de la visión divina a otra vida, a un paraíso adonde se remite toda gloria y toda verdadera práctica, ya que sólo allí ocurrirá el goce en acto. Los sentidos serán restaurados el día de la resurrección. Los cuerpos resucitarán perfectos para una plena vida en la gracia. En el paraíso de Santo Tomás se vuelcan, para Cemí, “apetito, posesión, y delectación frutal” (268). ¿Qué sugiere? Que para Santo Tomás los genitales no son los órganos primeros. Para él prima la posesión y delectación gustativa, que bien podía experimentar mientras pensaba y escribía. Vale decir, su idea de un paraíso futuro está nutrida por los alimentos terrestres con los que engordaba cada día.

José Cemí rescata el banquete de los sentidos para la fiesta del intelecto. No en vano esta novela se llama Paradiso.

El pecado nefando era la menor de las preocupaciones para Santo Tomás. Por eso, tal vez, lo juzga con menor severidad.

Para él, los peores pecados son los que incluyen malicia, el propósito deliberado de hacer daño. Éstos son, entre los pecados de lujuria, el adulterio, el estupro, el sacrilegio, el rapto. Son más graves porque contrarían el sentir del otro, o abusan con daño a la víctima.

Si no se quiere mal al prójimo, si no se le hace daño, entonces cabe al menos más caridad en el pecado contra natura. La posesión por culo está mal, tanto a macho como a hembra.

¿Con qué puede compararse?

Santo Tomás lo compara con otro pecado contra natura, fornicar con las bestias. La moral cierra los caminos de eros, pero aquí, al expulsar al pecador, lo expulsa fuera del mundo de los hombres, hacia las bestias.

En este punto, Foción interrumpe a Cemí.

¿Qué especie de pecado es éste, contra natura?

¿Lo que hacen las bestias? Pero las bestias, para el dogma teológico cristiano, no pecan. Sólo los hombres pecan y son pasibles de culpa. Al devenir animales, estos individuos quedan libres de pecado.

"Si es bestialismo -y las bestias no pueden pecar- no es pecado en el hombre bestia que lo comete" (268). Por lo tanto será una bestia el homosexual, pero no un pecador.

José Cemí responde: en efecto, si los homosexuales son bestias, es que Santo Tomás no piensa admitirlos en el paraíso con esa mancha. Si son bestias, no resucitan.

Cemí alude a otro caso controvertible concerniente a la noción de cuerpo perfecto para el aquinatense. Se trata de los eunucos.

Si el cuerpo resucita íntegro, "es plausible pensar -agrega Cemí- que los eunucos serán retocados, enderezados y mejorados de voz” (269). 
Esta consideración irónica desencadena una hilaridad irreprimible.

¿Cuál es el cuerpo perfecto? ¿El que tiene los genitales intactos? ¿ Se restituirán el pene y los testículos a todos los eunucos para que se los calcen de nuevo en el paraíso? Y, ¿qué pasará (podríamos agregar hoy) con los transexuales?

Hasta avanzado el siglo XIX, para conservar su voz, los papas castraban a los niños del coro Vaticano. ¿Qué mantendrán en el paraíso los coristas, los testículos arrancados o la voz angelical?

Estas aporías dejan al pobre Santo Tomás turulato. Según Cemí: “Declaró que sus luces no le permitían ver claro en ese misterio" (269).

Foción termina el diálogo afirmando: me divirtió tu presentación de un Santo Tomás acorralado en contradicciones y absurdos, y por lo tanto "heterodoxo".

El diálogo de los tres amigos acerca del eros busca soslayar la máquina binaria, recurriendo a un eros primigenio de lo semejante. Aparta el error de la costumbre, apunta al despliegue del paideuma, la respiración cósmica, prolongada en el dromenon, poder de hecho, "hecho realizado", práctica, teorema que camina, baile.

La conversación acerca del homoerotismo se había abierto a partir de un hecho escandaloso: el coito de dos atletas. Ahora se cierra con otro coito, esta vez entre un hombre y una mujer.

Fronesis sólo puede poseer a Lucía tapando su vagina con una camiseta y proyectando sobre ésta, a modo de una pantalla de cine, su propia fantasía de lo semejante, la única capaz de excitarlo: un hombre dios construido con notable detalle y exótico diseño.

La vagina en primer lugar le espanta.

Ve en esa repugnante, temible y desagradable zona: un terreno tajeado, zanjas de negra y hostil vegetación, muy lejos de atrayente ("un yerbazal picoteado", "una estribación retorcida”, "un terreno carbonífero", "un informe rostro fetal, deshecho, lleno de cortadas, de costurones”, 273). Todo lo cual, no puede evitarlo, le provoca "náuseas". Ante panorama tan tétrico, teme volverse impotente. Inventa entonces un truco: se quita su camiseta blanca, recorta un círculo y en el medio del círculo hace un agujero. Pone el trapo sobre el vientre de Lucía, y sin tener que ver ni vientre ni vagina, fantasea sobre esa pantalla de proyección. Alucina, libre, mientras copula, a un dios hombre hecho de partes relumbrantes. Su atractivo no es común. No es un hombre, es otra cosa, es el andrógino, no marcado por el género. El "hombre dios”, la fantasía de Fronesis, fetiche inmanente de su deseo, está revestido de un poder que emana de su atuendo y figura. Es el fetiche que Fronesis necesita para excitarse y copular dentro de un vientre escalofriante y recubierto.

El hombre dios tenía las orejas trabajadas en mosaicos azules, tenía un collar de oro con espaciosidades de caracoles corroídos por el salitre yodado, reverso en 
los olores de la canela. Las espaldas con unas correas donde parecía que corrían unos ratones en llamas. Las rodillas traía envueltas en el moteado del tigre donde colgaban caracoles con olores difíciles [...]

La mitra que usaba tenía alteraciones moteadas, jaspe de tigre. La cara de negruras y todo el cuerpo de un ébano puntiagudo. Una sobrepelliz muy ondulada de ornamentos le caía sobre la espalda y los pectorales, marcándole la glútea y la vulva verdosa. (296)

Imagen glam abigarrada, espacio construido de adornos y de olores, no es fijo, sino mercurial; tiene la vulva en el culo, vulva anal del glúteo: "marcándole la glútea y la vulva verdosa”.

"La glútea y la vulva verdosa”: estamos de nuevo ante Yoculo, aquel volcán islandés. Las úes hollan la hundida entrada.

Éste es el eros de lo semejante para Fronesis. Su “objeto” no es humano (no es su amigo Foción, por ejemplo) sino hipertélico, impersonal, una prótesis más amplia que cualquier identidad de hombre o de mujer.

\section{Fuera de GÉNero: JuAn Carlos OnetTI}

Los críticos suelen detenerse en el carácter "existencial" -es el término que algunos usan- de las atmósferas y situaciones de Onetti, o bien en los procesos de construcción de sus ficciones, o en la índole compensatoria del escribir con respecto a las pérdidas y el deterioro de los cuerpos y las almas de la gente.

Pocos han reparado en el funcionamiento erótico de sus relatos, salvo para indicar, a veces de soslayo, con desconfianza o censura, sus preferencias por la mujer joven. No han advertido que esas preferencias implican una indefinición, una ambigüedad extraña.

En la novela corta El pozo, de 1939, el narrador señala, de un modo que vale para el resto de sus obras, una claudicación temprana de la gente, que se amolda a los requisitos impuestos por las normas de convivencia. "La gente absurda y maravillosa no abunda; y las que lo son, es por poco tiempo, en la primera juventud. Después comienzan a aceptar y se pierden” (25).

El insertarse en una relación de familia o en un régimen de trabajo coarta las posibilidades de un cuerpo y una mente jóvenes. Al contrario, se privilegia aquí el comportamiento disidente, la actividad marginal o el "derecho a la pereza" (sobre el cual había escrito Paul Lafargue) como instancias salvadoras. Ese margen, lo averiguará el lector de ésta y las obras sucesivas de Onetti, puede mantenerse gracias a una actitud contemplativa capaz de abrir una dimensión interior, y de la cual escribir es una instancia particular, aunque por lo visto necesaria en la economía de Onetti. 
Las mujeres, indica el protagonista de El pozo, suelen "morir" a la edad temprana en que se resignan a cumplir el programa que les asigna el grupo:

He leído que la inteligencia de las mujeres termina de crecer a los veinte o veinticinco años. No sé nada de la inteligencia de las mujeres y tampoco me interesa. Pero el espíritu de las muchachas muere a esa edad, más o menos. Pero muere siempre; terminan siendo todas iguales, con un sentido práctico hediondo, con sus necesidades materiales y un deseo oscuro y ciego de parir un hijo. (25)

Para Lewis Carroll, las mujeres perdían interés antes que para Onetti. Carroll encontraba en las niñas una intrepidez de pensamiento, una curiosidad viva, un criterio calibrado. Esas características luego se evaporaban. Cuando Carroll recibía en sus habitaciones a sus pequeñas amigas tomaban un té fuertísimo. Y Alicia en el país de las maravillas describe los efectos distorsionantes, como de droga, que condicionan las percepciones del personaje.

Después predomina el programa que consiste, según Onetti, en una busca de seguridad y el compulsivo propósito de perpetuar la especie. En función de lo cual las jóvenes relegan sus posibilidades, su apertura. Por cierto, el punto de vista de las narraciones de Onetti es estéril en el sentido de que no considera -parece incapacitado para considerar- la experiencia de la preñez y su enganche específico para la mujer. Desde el punto de vista de sus narradores, la preñez desequilibra la ambigüedad del llamado erótico, que rehúsa elegir, con una fuerza explosiva que conmueve todo el edificio de la cultura.

En La vida breve (1950), leemos que una antigua amante del protagonista lo viene a visitar estando preñada. Él advierte cómo esa mujer se ha vuelto alguien diferente, que le repugna. Para empezar, ha perdido su ambigüedad adolescente. Ha adquirido un aspecto inequívoco de hembra por tener el vientre hinchado. Pero además su mentalidad ha cambiado, ha variado de criterios y opiniones. Antes "eras maravillosa, eras el absurdo, estabas como nadie unida al entusiasmo y al misterio de vivir".

Se oponen aquí un vivir intenso y sin prejuicios, que rompe las costumbres y reinventa la moral, a una bondad edulcorada y de receta, que esconde la incomprensión y la intolerancia, bajo el pretexto de defender la vida que porta en su seno:

Está loca, no tiene derecho a esto, a convertirse en una ruina grotesca [...] Porque así como el traje recto y flojo es el uniforme de todas las inminentes madres del mundo, el pequeño sombrero sin adorno, ceñido como un casco, proclama la resolución de la pureza, el desprecio por las posibilidades sensuales de la vida, su adhesión al deber y a la soberbia estupidez. (215) 
El amor y la maternidad, para Onetti como para el filósofo ruso Vladimir Solayov, están completamente separados. Los verdaderos amantes, escribe Solayov, suelen ser estériles.

Onetti rechaza el peso inercial de la tradición cristiana, y en general de las tradiciones monoteístas, que consagra los sexos como esencias, las identidades de género como inamovibles, y la exclusiva justificación del sexo en aras de la procreación.

Por contraste, en esa misma novela, el protagonista cultiva una relación violenta con su vecina de apartamento, la prostituta Queca. Queca sabe de qué se trata. Dice: "Si los nombro los mato, les voy diciendo a cada uno el nombre que tiene" (178). Dar nombre, dar identidad, equivale a matar.

En el cuento "Bienvenido Bob” el narrador se enamora de Inés, una muchacha aún no contaminada por los requerimientos de la mujer madura. El hermano de ella, Bob, es un adolescente rubio de ojos azules, atractivo y suave, casi idéntico a la chica. El protagonista cree ver los rasgos de Inés en el rostro del muchacho, y viceversa. Quiere casarse con Inés para estar cerca de él, el muchacho lo intuye y rechaza al maduro que lo asedia, impidiendo la boda con su hermana. Bob e Inés representan vertientes simétricas y complementarias de un deseo andrógino, de un deseo no marcado por el género.

Al ser rechazado, el protagonista de este cuento inaugura la serie de héroes adultos que en Onetti pasan del amor al odio al sentirse excluidos del círculo mágico de una promesa andrógina. Bob, el rubio adolescente de "ojos lustrosos", promisor pero inalcanzable, pierde, con los años, su aura ambidextra, se integra al mundo de los adultos, se casa, llama a su gorda mujer "mi señora”, trabaja en un vulgar empleo "hediondo", y bebe para olvidar que ha perdido su magia de juventud, "protegiéndose la boca con la mano sucia cuando tose”. El protagonista lo acompaña al bar, donde se emborrachan. Se han hecho amigos denigrados por el mismo curso de las cosas, la promesa se ha vuelto agria y no se cumplirá.

Pero esta decadencia de Bob es, para el protagonista, que ha contemplado y no olvida su primer aura, que ha sufrido el rechazo y odiado con profundidad, una dulce venganza, una increíble vida en el amor que resiste la decadencia y el tiempo:

Nadie amó mujer alguna con la fuerza con que yo amo su ruindad, su definitiva manera de estar hundido en la sucia vida de los hombres. Nadie se arrobó de amor como yo lo hago ante sus fugaces sobresaltos [...] No sé si nunca en el pasado he dado la bienvenida a Inés con tanta alegría y amor como diariamente doy la bienvenida a Bob [...] Puedo asegurar que entonces mi corazón desborda de amor y se hace sensible y cariñoso. (25) 
El cuento "Historia del caballero de la rosa y de la virgen encinta que vino de Liliput” plantea, desde su título, una contraposición. El muchacho y la muchacha no conforman aquí las dos vertientes equivalentes en su atractivo, como Bob e Inés. Aquí la mujer aparece afeada por el embarazo que, como a la mujer preñada de La vida breve, "la excluye de las posibilidades sensuales de la vida". Se ha empequeñecido, se ha vuelto una enana deleznable. El muchacho, "el caballero de la rosa”, en cambio, encarna el imán de una atracción tan inquietante como universal. El pueblo entero -hombres y mujeres- lo acecha fascinado, dando valor a su ambiguo atributo ("rosa”).

En El astillero, el protagonista, Larsen, un viejo que está por morir, aún conserva ciertas esperanzas terrenas, en particular la de contraer matrimonio con Angélica Inés, la hija loca o boba del dueño del astillero. Esta otra "Inés” está tocada por una gracia extraña y es una eterna adolescente, que no deviene adulta jamás. De esta mujer "rara" o diferente se dice varias veces en otra novela (Juntacadáveres) que tiene "pecho liso y cola de muchacho". Aquí descubrimos la clave de su atractivo.

Larsen vive en una pensión. El muchacho que le lustra los zapatos y limpia el cuarto se aproxima a él con aire invitante, una gracia tentadora y pasos de baile. Larsen, que ya se está despidiendo de la vida, le regala cincuenta pesos sin exigir a cambio ninguna prestación. Según su código bravucón y limitado, que un muchacho sea tratado como una muchacha "es lo último que le puede pasar a un tipo". Descarta la oferta silenciosa del chico y le cuenta, para educarlo, un episodio que ha presenciado antaño en Buenos Aires. Un joven florista, parecido al adolescente de la pensión, es manoteado en la cola por dos policías:

Se había acercado con los ramitos de violetas [...] Cuando los vigilantes lo tocaron no podía disimular porque todo el mundo lo había visto y no podía enojarse porque la autoridad es la autoridad. Así que hizo la cosa más triste de este mundo: nos mostró una sonrisa que ojalá dios no permita que tengas nunca en la cara. (225)

La relación entre Larsen y el chico limpiador queda irresuelta, en suspenso, del mismo modo que el cortejo de Larsen a la inaccesible Angélica Inés carece de resultados. El ambiguo muchacho y la ambigua mujer representan dos caras de un deseo equivalente e imposible, por lo inacabado, cuyo objeto es el andrógino, el fuera de género.

En Dejemos hablar al viento Medina, el comisario del pueblo (otro "vigilante"), queda fascinado por su hijo putativo, el joven rubio Seoane. Lo cerca y lo hostiga, hasta que lo sorprende durmiendo en un galpón y prende la luz, como Psiqué, para atisbar el cuerpo desnudo de Eros. Medina sostiene a la vez un affaire con la lesbiana Frieda, a la que llama "puta ambidextra". Seoane y Frida se vuelven 
amantes, uniendo los bordes o vertientes del deseo andrógino. Su fusión equivale a la de los hermanos Bob e Inés, dos caras de la misma moneda, que conforman juntos el objeto imposible de un amor sin género, que se incuba y se pudre en el odio. Medina mata a Frieda y acusa a Seoane del crimen. Obtiene así una venganza, una satisfacción de su odio semejante a la del narrador de "Bienvenido Bob" al fin del cuento.

En un relato inacabado y caótico de 1936, “Los niños en el bosque”, hay varios indicios de relaciones homoeróticas entre los infantes.

Este cuento preludia el desconcierto de "Bienvenido Bob". Tanto Coco como Bob se parecen a una mujer, a una muchacha, a una hermana. Y esto es inquietante. Asoma aquí un elemento indecidible, femenino y masculino, entre niño y niña, "un aire”, "una luz”, una oscilación perpleja que confunde los géneros y despierta el deseo: "El Coco [...] seguía riendo, las manos hundidas en los pequeños pantalones, yendo y volviendo", mientras otro muchacho observa el "óvalo rosa y afinado de su rostro”, tratando de descubrir allí un rostro femenino:

buscando en él la cabeza orgullosa y larga de la muchacha del balcón. Nada. Acaso la nariz, corta y abierta, apenas vuelta hacia arriba. Tampoco. Sólo que la relación consistiera en algo que no es ella ni el Coco, la estela que dejan en el aire al moverse, esa angustia fina de la cabeza a un lado, la luz en los ojos de miel. (267-68)

Su amigo "miró al chico [Coco de nuevo] que trepaba al cordón de la vereda, para saltar en seguida a la calle con los pies juntos. Tenía las nalgas desbordando del pantalón y una huella oscura, profunda y dulce señalaba la nuca”. Esa visión desde atrás excita a su amigo, y Coco se vuelve una presa para ser agredida o violada tanto por él como por los demás muchachos.

De otro de los chicos leemos: "Este hijo de puta tiene ojos de gacela" (271). Lo cual excita un deseo de posesión y de agresión al mismo tiempo: "Algo tiene que pasar: algo como morirme o pisarle la cara a Lorenzo" (271).

Entonces el Coco pregunta a su compañero: “-¿¿Y qué te importaba? -¿Cómo? -Claro: si yo hubiera querido. También vos; anduviste con el rubio de los ingleses y con Juan José”. Y el aludido responde: "Pero mirá: no sé si entendés. El rubio y Juan José ya eran así. Vos no: sos mi amigo”. (274)

El Coco sigue tentándolo, sin embargo: "El Coco se le acercó al pecho, arreglándole la corbata”, pero su amigo "lo separó, tomándolo de los hombros, clavándole los ojos malos y desconfiados:-¿¿Por qué me hablás así, eh? ¿Por qué hablás de esa manera?” El Coco habla al parecer de un modo amanerado. “-Si yo no hablo de ninguna manera” (277). 
Y después: "La cabeza negra y lustrosa” de Coco, "la piel suave y el olor de la blusa lo hacían bueno y tierno". El otro muchacho intenta respetarlo: "Se estaba salvando en aquella única cosa limpia de su vida: su tarea de apartar al Coco de los hombres inmundos de la esquina”, que sin duda lo desean y pretenden violarlo (277). Pero Coco, imprudente, persiste en ofrecerse: "El Coco aventuraba una mano hacia su cuerpo, en la sombra”. El otro "se alzó pesadamente, temblando de la rabia y el asco. Separó un puño, lento, midiendo con los ojos entornados la cara del Coco, la pequeña nariz remangada que iba a golpear. Si lo mato me salvo", pensó, pero "el Coco, sin comprender, continuaba cerca, brillándole los ojos en la cara empurpurada, respirando afanoso por la nariz ofrecida y tan semejante a la de la chica reidora del balcón” (277). El otro piensa golpearlo pero no puede: “Caía, blando, el brazo [...] Luego, suavemente, sonrió en la sombra [...] En medio del agua viscosa se inclinaba por fin sobre la niña roja y bailadora” (que era el Coco). Lo cual lo hace verse a sí mismo "como un absoluto cochino; sucio y puerco. Eso; pero ahora del todo y para siempre. Ya no hay, no tengo llama que abrigar” (278).

Más tarde va caminando y oye pasos. Es Coco que lo sigue:

Lo vio pequeño y redondo, afanado por no quedarse atrás, estrechos los hombros, cortando con breves carreras el balanceo cadencioso del cuerpo. Recordó la próxima blancura [del cuerpo de Coco] en el monte oscuro [...] Rápido se inclinó: de una pechada brutal lo mandó doblado, con un tijereteo de las piernas desnudas y abiertas, cabeza abajo por el metro de orilla en declive que tocaba las aguas. Oyó que gritaba, el chapoteo y luego un llanto fácil y desconsolado, llorar de criatura que cierra los ojos cuadriculando una enorme boca negra. (279)

Deseo y odio: en la sociedad machista de su tiempo, los personajes de Onetti no encuentran paz cuando se sienten atraídos por esas presencias ambiguas: por un aire andrógino que, siendo maldito, por prohibido, no deja de ser el imán oculto o expreso de un eros ambidextro.

En el cabaret de El pozo, "un muchacho que se movía como una mujer se reía tocando valses en el piano con un medio litro que alzaba de vez en cuando, manteniendo la música ensordinada con un dedo solo y bebía riendo: -iCheerio! ... La voz del muchacho en el piano, cuando decía: ‘¿Cheerio!’ con el medio litro en el aire, era también de mujer” (23).

Estos ingredientes de atractivo en Onetti aparecen siempre como el fantasma ambiguo, irresistible, de algo que es a la vez hombre y mujer, Bob e Inés.

La mujer de "Esberj, en la costa", usa zapatos de hombre, igual que la mujer de la cabaña, en El astillero. Frieda no sólo es andrógina, sino también lesbiana.

La preferencia de los narradores o protagonistas de Onetti por la mujer joven tiene que ver con una indefinición, una ambigüedad extraña. Un cuento tardío, que 
publicó en El País de Madrid, “Jabón”, cuenta que un hombre va manejando un coche cerca de la frontera entre España y Francia, y en el camino levanta a alguien, que el protagonista ignora si es hombre o mujer. Lo ignora el protagonista y lo ignora el lector. La persona que sube al coche está envuelta en ropa floja que impide averiguar si tiene senos o caderas. El chofer que lo recoge cambia sus planes. Decide detenerse, alquilar una casa en un lugar cualquiera y vivir allí con el andrógino. Viven juntos unos días, en que el protagonista sigue obsesionado por el género de su huésped. ¿Es hombre o mujer? Lo único seguro es el olor a pino del jabón con que se baña. Esta obsesión lo persigue hasta que en un momento siente que ya no quiere saber. Todo en el otro es equívoco. El cuerpo, el rostro, la voz. Carece de los signos de adulterada femineidad de un muchacho invertido o travestido, carece asimismo de la soterrada virilidad de una lesbiana. Pero él ya lo acepta así, es lo indecidible puro, un comienzo que lo atrae. Entonces resuelve que no quiere saber. Más aún, tiene miedo ahora de que un acento, una frase, cualquier gesto imprudente revelen su género, afichen una identidad a partir de la biología.

Y así prosigue, en la paradisíaca incertidumbre de un cuerpo no marcado por el género. El andrógino de "Jabón” en el cual culmina o se cifra del modo más sintético el deseo onettiano, suscita miedo (“jabón”) ante una superficie resbaladiza e indeterminada ("jabonosa”). A estas alturas de la carrera y de la vida de Onetti, al menos en el idílico pinar del cuento "Jabón”, ya no suscita odio o rechazo.

BiBLIOGRAFÍA

Caminha, Adolfo. Bom-crioulo. São Paulo: Editora Atica, 1983.

Cándido, Antonio. Introducción a la literatura de Brasil. Caracas: Monte Ávila, 1968.

Lezama Lima, José. Paradiso. Buenos Aires: Colección Archivos, Fondo de Cultura, 1988.

Esferaimagen: Sierpe de Don Luis de Góngora. Barcelona: tusquets, 1970.

Onetti, Juan Carlos. El pozo. Montevideo: Calicanto, 1977. La vida breve. Buenos Aires: Sudamericana, 1968.

"Bienvenido Bob". Cuentos completos. Buenos Aires: Centro Editor de América Latina, 1973. El astillero. Madrid: Cátedra, 1995.

"Los niños en el bosque". Tiempo de abrazar (y cuentos). Barcelona:

Bruguera, 1986. 267-268.

“Jabón”. Cuentos Completos. México, DF: Alfaguara, 1994. 439-441.

Rosa, João Guimarães. Grande sertão: veredas. Rio de Janeiro, 1984.

Solayov, Vladimir. The Meaning of Love. Londres: the Centerary Press, 1945. 